Mário César Lugarinho*

Universidade de São Paulo

\title{
Cânone e Crítica: Superações
}

Resumo:

A emergência dos estudos culturais, dos estudos pós-coloniais e decoloniais, dos estudos de gênero e dos estudos queer propiciou, ao longo da segunda metade do século $\mathrm{XX}$, alteração profunda nos paradigmas das Ciências Humanas. Neste artigo, procuramos observar essa "evolução" tendo em vista o conceito de cânone e a consequente superação de sua tradição de exclusão.

Palavras-chave:

cânone, crítica literária, história da cultura

\section{Abstract:}

The emergence of cultural studies, post-colonial and decolonial studies, gender studies and queer studies led, throughout the second half of the 2oth century, to a profound change in the paradigms of Human Sciences. In this article, we seek to observe this "evolution" in view of the concept of canon and the consequent overcoming of its tradition of exclusion.

Keywords:

canon, literary criticism, culture history

Os estudos literários, nas últimas décadas, sofreram, como se sabe, um amplo processo de deslocamento de sua área de atuação, muito promovido pela transformação dos paradigmas das Ciências Humanas. Já vai longe o tempo em que unicamente interessava ao crítico descrever as características estilísticas do texto ou o seu funcionamento em termos semânticos ou, ainda, os seus aspectos morfológicos, cujos elementos estruturais eram exaustivamente evidenciados.

De igual maneira, o texto literário deixou de ser o objeto privilegiado pelo crítico em favor do discurso literário, na medida em que as suas condições de produção é que passaram à ordem do dia. Da descrição das condições de produção passou-se a elaboração de uma crítica mais ampla, na qual a escritura literária não é mais o único objeto privilegiado de análise - esta se dá através do reconhecimento do nicho cultural ocupado pela obra e da sua capacidade de articulação com outros saberes a fim de que seja elaborada uma análise da cultura, da qual a obra emerge e para a qual se destina. 
As Ciências Humanas, em geral, e a crítica literária, em particular, passaram a se constituir como saberes necessariamente interdisciplinares, criando campos abrangentes nos quais alguns saberes e objetos ganham relevo, de acordo com o objetivo da análise, mas que são, evidentemente, tomados a partir de um olhar relacional que se solidariza com outros saberes e objetos. É a constituição do projeto de História da Cultura, no qual o termo "cultura" é amplificado para compreender toda a atividade humana e o termo "história" é tomado a partir de seu caráter concatenador, concedido pelo modelo da narrativa historiográfica (Barreto 1985: 270).

A História da Cultura é ambiciosa: ela convoca os saberes científicos já constituídos, mesmo privilegiando um único objeto. Fruto da revolução metodológica no âmbito da ciência histórica, que superou os primados do historicismo e ampliou o materialismo histórico, a História da Cultura não pretende instituir uma história total, porque reconhece os seus limites epistemológicos, mas perceber as relações mantidas entre um dado objeto e seu contexto. A História da Cultura, dessa maneira, tornou-se modelo para os estudos interdisciplinares, ao mesmo tempo em que se tornou o campo epistemológico por onde transitam as práticas investigativas das Humanidades.

As Ciências Humanas, afinal, passam a se perceber como uma reunião de saberes que dispõem de autonomia, mas que se reconhecem incapazes de obter uma descrição exaustiva de seus objetos se insistirem unicamente em seus próprios princípios e campos investigativos. Nesse contexto, destacam-se os saberes que se constituíram em torno dos estudos da linguagem (a linguística, a teoria e a crítica literária) e que recorreram a princípios interdisciplinares para a sua (re)constituição em bases científicas durante o século XX. É notória a forma com que o pensamento de Claude Lévi-Strauss tomou a linguística estrutural como modelo de análise dos mitos e das relações de parentesco (cf. Lévi-Straus 1975), bem como, pouco mais tarde, os seus estudos fomentaram os estudos da narratologia nas décadas de 1950 e 1960.

A crítica literária, reconhecida como atividade das Ciências Humanas, teve, então, o seu caráter interdisciplinar, multidisciplinar e transdisciplinar sobrevalorizado. Com isso, ao invés de se observar o esvaziamento do conceito nuclear de literariedade, percebe-se a instrumentalização da teoria e da crítica literárias para além dos espaços tradicionais nos quais se localizam os objetos literários.

O privilégio que o método estrutural dera à descrição das obras literárias (e à solidariedade com a Linguística Estrutural) determinou uma direção bastante inesperada para a análise literária e para muitos analistas, que tinham ao seu lado uma tradição já consolidada pela estilística ou pela sociologia da literatura. Vale recordar que esta corrente crítica dedicava-se muitas vezes à análise de processos que explicassem a maneira como uma literatura nacional se articulava com a história nacional. Paradigmático é o ensaio "Narrar ou descrever", de György Lukács (1971), mas são os estudos de Roberto Schwarz, "As ideias fora do lugar" (1977), e de António José Saraiva, "A tertúlia ocidental”, (1991), que melhor exemplificam, no Brasil e em Portugal, respectivamente, essa abordagem. Cada um a seu turno, buscou compreender a produção literária brasileira e portuguesa do século XIX, debruçando-se por sobre a História de seus países no mesmo século XIX, e assinalou como a literatura e a sociedade discutiram aporias políticas, sociais e culturais. 
A sociologia da literatura dependia do reconhecimento de uma díade fundamental, literatura e sociedade, em que se verificava uma relação imediata, na medida em que compreendia o texto literário como uma forma não de reflexo, mas de reflexão a respeito da sociedade (Moreiras 1996; Ribeiro 2008). Tal perspectiva derivara de uma nascente crítica literária do século XIX, quando intelectuais se interrogavam a respeito da constituição de valores nacionais no texto literário. Tais valores, antes reconhecidos como morais, na medida em que estavam subjugados a uma perspectiva ético-religiosa, passaram a ser considerados a partir de expressões do moderno estado nacional em formação, que se embutiam na identidade de classe burguesa. Além disso, havia a busca pela especificidade cultural dos povos europeus e pela construção de uma narrativa histórica que previsse e justificasse a emergência e o protagonismo da burguesia. Foi nessa época que a Literatura emergiu como uma instituição social (e nacional), porque expressava à sociedade os valores norteadores da cultura nacional. Se a Literatura, desde a paideia, no mundo clássico, era manancial que modelava comportamentos, por seus aspectos éticos e morais, ela também se prestaria a uma exemplaridade pedagógica para as classes emergentes nas sociedades europeias do século XIX.

Mas a dinâmica das transformações sociais e culturais que aquele século experimentou, e que continuaram ao longo do século XX, acrescido das experimentações artístico-literárias das vanguardas, não foram passíveis de uma instrumentalização abrangida pela sociologia da literatura. Faltava-lhe o reconhecimento de que seus paradigmas estavam sendo colocados em causa pela própria História, a que privilegiava. Ao lado da emergência de novas classes sociais que expressavam a exemplaridade da identidade nacional (a burguesia e, posteriormente, o proletariado), outras formas de identificação se constituíram, como o gênero e a etnia, o que punha em causa seus paradigmas, já que a centralidade da nação e dos valores nacionais era relativizada e colocada em função desses marcadores sociais, culturais e históricos.

Mas tal prática não seria tomada de maneira indiscutível. Antonio Candido, em "Crítica e sociologia" (2006), apontava que tal metodologia de análise colocava de lado o valor e o significado da obra literária, visto que seriam submetidos a uma análise unicamente sociológica. ${ }^{1}$ Fiel ao princípio de autonomia da arte e da literatura, Candido, nesse ensaio, buscava encontrar uma síntese que atendesse tanto ao princípio norteador da crítica, o valor estético da obra, quanto ao interesse de sua correlação com o meio social onde a obra é promovida. Candido propunha a constituição de uma metodologia que fosse capaz de devolver à obra literária seu estatuto artístico, ao se dedicar à análise do texto em si, em que fossem levados em consideração os juízos de valor ao lado do exame ideológico dos discursos.

O problema do valor estético da obra literária parece ter sido o principal obstáculo para que a sociologia da literatura se tornasse um consenso para a crítica literária. Isso porque a dificuldade de encontrar um equilíbrio na atividade crítica que distribuísse a ênfase entre o estudo imanentista e o estudo do contexto, durante muito tempo, pareceu impossível. O estudo da estética literária, que encontrou na estilística, no início do século $\mathrm{XX}$, forte ponto de apoio e, pouco mais tarde, na enunciação do conceito de "literariedade", pelos formalistas russos, sofreu um debate contínuo, durante o último século, porque tanto a História, quanto a crítica 
Cadernos de Literatura Comparada

Cânone e Crítica: Superações

sociológica colocavam em causa o reconhecimento da autonomia absoluta da obra de arte e da literatura.

Com isso, o conceito de valor estético da obra literária, que asseguraria à crítica literária a sua autonomia frente aos outros campos disciplinares, passou também a ser relativizado ao ser observado no contexto cultural onde se constitui - como apontaram, notadamente Walter Benjamin e Theodor Adorno, dentre outros. Os pensadores de Frankfurt superaram os paradigmas ofertados pela constituição do estado nacional, reconhecendo a dinâmica históricocultural das grandes narrativas que atravessavam toda a cultura ocidental: a modernidade e a consequente instrumentalização da razão. Ao reconhecerem o movimento mais amplo, no qual a emergência do Estado nação, a ascensão da burguesia e o aparecimento do proletariado eram apenas cumes de um iceberg, constituíram análises nas quais o contexto do surgimento da obra de arte e da obra literária eram concomitantemente conjugados, por exemplo, às suas histórias, aos seus procedimentos intrínsecos e às suas formas de circulação. Dessa maneira, a arte e a literatura, mas também a história e a filosofia, a física, a química e a biologia, a psicologia e a sociologia, eram saberes colocados em causa. Por terem se submetido à razão, e consequentemente terem se tornado objetos de uma ciência, foram instrumentalizados em prol da mesma modernidade que substituía o mito.

Aqueles que defendem o primado do estudo da estética na análise literária são devedores da instabilidade que se instalou nas formas de produção literária ao longo dos séculos XIX e XX. Apoiaram-se na tradição que emanava do conjunto de obras que eram selecionadas para comporem o cânone literário, já que essas obras serviriam como orientação para o reconhecimento do que deveria ser ou não válido como estético. O formalismo russo, ao propor o procedimento parodístico como aquele que constitui a dinâmica da história literária, determinou o cânone como uma sucessão de séries que se interpenetram e que dialogam entre si a partir de procedimentos e temas recorrentes ao conjunto canônico.

A história literária, subsumida pelo cânone, seria constituída por um sentido de permanência, um continuum, mesmo quando sofresse a interferência da paródia, já que mesmo contestado por tal procedimento, o cânone se afirmaria e não sofreria mutações relevantes, mas apenas acréscimos significativos de obras que poderiam, desde a sua gênese, serem previstas, mesmo quando apontassem para sentidos contrários. É o que Yuri Tinianov apontara ao enfatizar a paródia como o motor da evolução literária, que, pela reiteração de temas ou técnicas, manteria a força canônica, apesar de desautomatizá-lo (Tinianov 1978).²

A formação dos cânones literários é devedora de uma política ostensiva de silenciamento. Já se compreende, com certa exaustão, que os cânones são formados, principalmente, a partir de elementos exteriores ao literário, de maneira que expressem algum conceito que a ele se sobreponha (cf. Jara \& Talens 1987). Harold Bloom (1995), em contrapartida, defendeu que os cânones são formados a partir de critérios estéticos que se apoiam sobre considerações ditas universais. A provocação de Bloom ao invés de intimidar, oferece uma rota segura de investigação na medida em que as formações discursivas que sustentam o edifício canônico forem submetidas às formações ideológicas. 
A exclusividade do critério estético e, por conseguinte, do filosófico, que orientaria as definições canônicas cai por terra ao serem percebidas como orientadas para sentidos outros que não pressupõem o estético. A presença do critério estético é certa, no entanto a própria estética é historicizada e submetida aos mesmos princípios que governam aqueles que nela investem (cf. Ferry 1994).

Tendo sido projetados a partir do momento em que a sociedade burguesa, no século XIX, reivindicava sua autonomia histórica e (re)inventava a Literatura, os cânones literários foram instrumentos da formulação de políticas do imaginário. São estratégias de poder para a criação de modelos sociais e políticos, postos em circulação pela literatura. Como evidente aparelho ideológico, no sentido de Louis Althusser (1992), aquelas estratégias definiram novas identidades sociais para a sociedade nascente.

A sociedade burguesa do século XIX, novidade no panorama histórico, econômico, político e cultural do Ocidente, precisou construir traços de continuidade histórica a partir do momento em que reconheceu que se encontrava apoiada sobre a ruptura com o Antigo Regime, o que era significativo prejuízo para o projeto de construção do Estado nação. Avesso às rupturas, porquanto quaisquer ameaças à estabilidade política e social criariam obstáculos ao modelo de desenvolvimento capitalista, o século XIX formulou suas políticas de imaginário como formas de institucionalização e de popularização dos conceitos de nação e de Estado Nacional.

Benedict Anderson (2008) relata o longo processo que se deu para a construção do conceito moderno de nação, que veio, ao longo do século XIX, a se confundir com a identidade cultural e histórica de uma determinada comunidade. Mas vale ressaltar que a palavra nação, conforme Afonso Marques dos Santos, "já existia durante o Antigo Regime, mas é com a Revolução Francesa que ela passa a ocupar um lugar central no novo direito público, sem que seja necessário ou possível defini-la" (Santos 1986: 9). No século XIX, com a emergência da sociedade burguesa, a nação foi a transposição jurídica e emocional da soberania do rei para uma entidade coletiva.

O período romântico confirma o conceito, institucionalizando-o. Filósofos e escritores românticos levantam a voz contra o "universalismo" das raízes greco-romanas da cultura europeia e levam a cabo a pesquisa das origens históricas e das especificidades culturais de cada povo europeu. Os movimentos que se seguem às independências das Américas, o pangermanismo, o pan-eslavismo e o movimento de unificação italiana seriam os resultados mais relevantes deste processo, inicialmente europeu, de busca de identidade e, por conseguinte, de origem.

Os conceitos de cultura popular, origem nacional, nacionalidade e identidade e consciência nacional são todos recorrentes ao termo nação, e confundem-se para que se justifique a existência de um estado nação e, também, dos indivíduos (monarcas) e entidades representativas (parlamentos, governos) que o materializam. Dessa maneira, a cultura popular, em contrapartida à cultura das altas classes, é percebida como o lugar em que estariam soterrados, sob os séculos de domínio do Antigo Regime e, por conseguinte, da aristocracia, os indícios autênticos da origem nacional de uma determinada comunidade. 
Cadernos de Literatura Comparada

Cânone e Crítica: Superações

A popularização da Literatura neste período, impulsionada pela nascente indústria cultural, implicou o estabelecimento de relações entre leitores distantes espacialmente entre si, que passavam a se identificar com os mesmos valores emanados por uma narrativa das suas origens comuns. É nessa teia de relações, tecida pela emoção popular e os objetivos políticos da burguesia, que foram formuladas a nacionalidade e o nacionalismo. Buscar a origem de um Povo era definir a biografia de uma nação e, portanto, conceber a sua História.

Ainda, segundo Santos, Gramsci teria considerado que esta maneira de se conceber a história pressupunha a constituição de um poderoso instrumento político para coordenar nas grandes massas os elementos que formavam precisamente o sentimento nacional. A concepção das histórias das literaturas, naquela altura, submete-se a esse propósito flagrante. Não será à toa que o cânone literário terá suas raízes entranhadas nas histórias literárias por conta da fixação e registro de obras que passam a merecer atenção de uma crítica nascente, por remontarem, segundo os propósitos da sociedade burguesa, a origem e a construção das nacionalidades.

É desnecessário remontar o processo de institucionalização da Literatura ao longo do século XIX e o seu consequente papel fundamental na construção do Estado nação e da sociedade burgueses. Vale assinalar apenas, que, para tanto, foi preciso a sua massificação e o concurso de uma classe específica, os "homens de letras" (Eagleton 199: 37), que reivindicava um discurso e um saber próprios. A emergência dos "homens de letras", seguida pelo desenvolvimento da intelectualidade como classe orgânica, são produtos de uma exigência dada pela criação dos estados nacionais, que via no seu concurso a possibilidade de vulgarização dos conceitos políticos e filosóficos que norteariam a sociedade burguesa. O desenvolvimento da crítica literária, durante o século XIX, através da imprensa, foi a forma encontrada para a transmissão do saber das classes ditas esclarecidas para a massa populacional das classes não letradas, alçadas, agora, à condição de leitores pela recém-criada indústria cultural.

A invenção da categoria do "homem de letras" punha em questão o processo de disseminação do conceito de nação e nacionalidade e sua correlação com o Estado politicamente organizado. Era certa para o homem burguês do século XIX a sua dupla condição de herdeiro de uma memória do passado aristocrático e de modernizador da sociedade que liderava. No entanto, a construção do Estado nação impunha uma contradição: ao mesmo tempo em que representava o Povo, incorporando-o a seu discurso e abolia a sociedade de castas do Antigo Regime, estabelecia uma continuidade histórica, mesmo que fictícia, entre os diversos estratos sociais e culturais que o compunham.

Tendo em vista que a instituição literária era veículo de propagação desse processo, sua crítica seria capacitada a aproximar a nova massa de leitores da burguesia ascendente de uma herança cultural do passado. Entretanto, a crítica deveria decidir entre emitir seus juízos em nome do grande público, formado pela nova massa de leitores, ou em nome de uma minoria, baseada na tradição letrada e esclarecida. Por isso, o "homem de letras" não poderia ser um parceiro em posição idêntica ao seu grande público leitor. Sua função seria a de instruir, consolidar e confortar o público, ideologicamente desorientado, oferecendo-lhe esclarecimento ante as complexas transformações econômicas, sociais e religiosas do seu tempo, com uma postura 
veladamente propagandística, processando o conhecimento no mesmo ato de provê-lo. Terry Eagleton assevera:

O leitor de classe média é agora menos o colaborador e interlocutor do crítico em sua iniciativa de esclarecimento cultural e muito mais um objeto anônimo cujos sentimentos e opiniões devem ser moldados através de simplificação intelectual. (Eagleton 1991: 42)

Ao lado da modelagem dos sentimentos e opiniões da classe média, pouco depois, em função da sua necessidade de afirmação no âmbito universitário inglês, a crítica literária, já reconhecida como disciplina em que se veicula o saber literário, passou a enfatizar uma perspectiva nacionalista. É ela que abre espaço para a emergência de um modelo de cidadão profundamente identificado com a história e a cultura nacionais, representadas no Estado (Eagleton 1997: 40). A crítica também se torna responsável por assinalar as obras que compõem o cânone literário, porque o torna capaz de conferir aos cidadãos o seu devido lugar como representantes da nação e, consequentemente, do Estado. Ao mesmo tempo, travava uma árdua luta contra as Ciências e a Filosofia a fim de justificar a sua existência no âmbito universitário, recorrendo à construção de um juízo estético, porquanto vinha a indicar, comprovar e reconhecer um valor permanente nas obras selecionadas. A crítica tornava-se, assim, o resultado de uma composição de conceitos de fundo filosófico e de uma razão instrumentalizada pelo Estado, o que lhe conferia, no mínimo, um caráter ambíguo no momento de sua formação.

Com isso, cânone literário e identidade nacional passaram a compartilhar um mesmo campo semântico. A naturalização da relação impôs, continuamente, que fossem verificadas as estratégias regulares de construção de uma nacionalidade através do veículo literário. A relação "natural" entre ambos os termos foi tão profunda que chegou a determinar o juízo estético, que se pretendia isento, na medida em que os conceitos que nortearam a identificação da estética literária foram submetidos pela crítica aos elementos da originalidade e da identidade nacional. Mesmo as vanguardas e os modernismos foram postos a serviço da nacionalidade quando seus autores passaram, também, a participarem dos cânones, determinando novas tradições e procedimentos.

O valor estético que Harold Bloom (1995) defende como o traço fundamental a sustentar o cânone revela-se, frente à reflexão de Eagleton, como uma oportunidade histórica a que a crítica recorreu como forma de legitimar o seu discurso frente a instâncias detentoras de poder efetivo na instituição universitária. Além disso, uma investigação mais pormenorizada a respeito da discussão que a modernidade empreendeu a respeito do conceito de beleza e de estética é nada mais do que a prova de que a interferência humana e, portanto, da sua subjetividade, no conceito da beleza é tão flagrante quanto a superioridade "inquestionável" de Shakespeare ou Bach (cf. Ferry 1994).

O desenvolvimento de estudos que deixaram de lado as práticas tradicionais de análise da obra literária, e que passaram a considerar as relações com o contexto como parte também da obra, é devedor diretamente do conjunto de reflexões que foram disponibilizadas pela teoria 
crítica, pela sociologia da literatura e pela análise do discurso, criando um amálgama interdisciplinar que se aproximou diretamente da História da Cultura e que nela se instalou. Além disso, essas reflexões são aliadas ao desenvolvimento, no âmbito da universidade anglo-saxã, dos estudos culturais e, ao mesmo tempo, dos estudos pós-coloniais.

Naquela mesma década de 1960, e paralelamente ao que acontecia no pensamento francês, os estudos culturais se desenvolveram no âmbito dos estudos de literatura. Se no cerne da sociologia da literatura estão as indagações a respeito das relações entre a produção literária, o(s) sistema(s) literário(s) e a(s) sociedade(s); para os estudos culturais, o centro de discussões se encontra localizado para além do objeto artístico, nas palavras de Raymond Williams, conjugando o objeto e a sua formação, tratando-os de uma forma não hierarquizada (cf. Williams 1989: 151). Dessa maneira, compreende-se como, na década seguinte, os estudos culturais virão a se encontrar de maneira clara com o pensamento pós-estruturalista francês nas universidades norte-americanas. No fim, o estudo das obras de maneira intrínseca era abandonado em favor do estudo da formação dos discursos e das obras artísticas, por conseguinte.

Pode-se dizer, assim, que os estudos culturais evidenciam que os sistemas literários eram modelados não apenas por suas características estéticas ou estilísticas, mas por características de classe. Evidentemente, o conjunto de obras que se reconhece no interior de uma literatura nacional - considerada aqui como o cânone literário nacional -, é selecionado por permitir que determinado conjunto da população se identifique de maneira imediata, como já apontáramos ao recorrermos a Terry Eagleton $(1991 ; 1997)$ e ao seu estudo sobre o desenvolvimento da crítica literária no Reino Unido. A representação contínua da classe burguesa no interior de obras literárias determinou uma severa revisão literária e, por conseguinte, a construção dos cânones nacionais, já que se contrapunham a um modelo canônico clássico que se identificava com o Antigo Regime. Os estudos culturais, assim, emergiram numa década em que as classes trabalhadoras inglesas politicamente organizadas encontraram seu protagonismo político numa sociedade fortemente estratificada - ao mudar o eixo de poder, mudava a cultura e mudaram os objetos culturais, principalmente com a emergência da cultura de massa do século.

Além do processo que se desenvolve no campo das análises dos objetos culturais, deve-se levar em conta que eventos históricos sobredeterminaram mudanças continuadas no interior dos estudos literários, em especial, e das humanidades, em geral. Se a emergências das classes trabalhadoras inglesas e as revoltas estudantis de maio de 1968 são facilmente apontados como eventos de fundo dessas transformações paradigmáticas no seio das humanidades (os estudos culturais, o pós-estruturalismo), de igual maneira o processo histórico denominado de "descolonização", encontra-se no fundo dos estudos pós-coloniais.

A emergência das novas nações independentes, antigas colônias das potencias europeias, determinaram o aparecimento de um campo específico de investigação que passava a levar em conta, de maneira mais ampla, não apenas a cultura daquelas novas nações, mas principalmente a relação entre o colonialismo e a formação cultural da qual essas nações se erigiam. Mais recentemente, os estudos pós-coloniais foram estendidos às culturas dos países dominantes na medida em que compreenderam que o colonialismo é um fenômeno histórico de mão dupla 
e que atinge tanto a cultura do colonizador quanto a cultura do colonizado.

Costuma-se apontar o desenvolvimento dos estudos pós-coloniais a partir da contribuição que Stuart Hall teria dado ao "Centre of Contemporary Cultural Studies" da Universidade de Birmingham, aliada, mais tarde, à contribuição de Edward Saïd, quando da publicação de Orientalismo (Saïd 1990). ${ }^{3}$ Segundo Sergio Costa (2006), em ambos os autores é visível a relação mantida com o pensamento de Foucault e Derrida, cujos pensamentos circularam nos países anglo-saxões de maneira bastante intensa. Assim, levando em consideração que toda enunciação vem de algum lugar definido por território, classe, gênero ou etnia, Hall e Saïd construíram uma crítica ao processo de produção do conhecimento científico, reconhecendo-o eurocêntrico. Isto é, a investigação científica daria, ao tratar de objetos não ocidentais, privilégios a modelos e conteúdos da cultura dos países europeus, o que reproduziria a lógica da relação colonial. Sérgio Costa afirma, também, que "tanto as experiências de minorias sociais quanto os processos de transformação ocorridos nas sociedades 'não ocidentais' continuariam sendo tratados a partir de suas relações de funcionalidade, semelhança ou divergência com aquilo que se definiu como centro" (Costa 2006: 117).

As práticas investigativas da Literatura Comparada eram atingidas diretamente pela reflexão dos estudos pós-coloniais, especialmente quando o analista se debruçasse por sobre conjuntos de obras que, ao serem comparados, reunissem textos oriundos de literaturas europeias e de literaturas nacionais de países que emergiram do colonialismo. Com os estudos pós- coloniais, a hierarquia possível entre esses conjuntos seria posta de lado, na medida em que, como primeiro pressuposto, haveria o abandono dos conceitos de causalidade, funcionalidade, anterioridade, ou originalidade, assim como acontecera anteriormente, no âmbito específico da Literatura Comparada, com o abandono do conceito de influência.

O procedimento crítico dos estudos pós-coloniais leva em consideração, portanto, que o conceito de "origem" deve ser abandonado, como Foucault propusera em sua genealogia (1978). Em seu lugar, leva-se em consideração o processo de formação discursiva, isto é, se não é considerada a anterioridade de uma obra sobre outras obras, o que localizaria a publicação mais antiga no lugar cronológico da "origem" e, por isso, prevalente e doadora de sentidos às que lhe sucederam, deve-se observar o processo de formação discursiva que as atravessa e as reúne. 0 conjunto só é reconhecido em função do(s) discurso(s) que se dispersa(m) por entre as obras e nas obras.

Assim, os estudos pós-coloniais, mais do que uma disciplina ou ciência, é um campo abrangente de reflexão por onde a crítica transita e que tem por valor principal a construção de um olhar crítico, senão desprovido dos modelos tradicionais de investigação, mas problematizador de si mesmo, ao colocar em suspenso os seus próprios métodos investigativos. Além disso, deve-se frisar: o prefixo "pós" da expressão "pós-colonial" não representa um "depois", no sentido cronológico linear; trata-se de uma operação de reconfiguração do campo discursivo, no qual as relações hierárquicas são significadas e ressignificadas (Ashcroft/ Griffiths/ Thiffins 1989: 2). 
Cadernos de Literatura Comparada

Cânone e Crítica: Superações

Constituindo-se como uma evidente ruptura crítica, ao inverterem (e embaralharem) os polos de investigação e análise, os estudos pós-coloniais melhor representam a superação dos paradigmas críticos da tradição. Ao seu lado, e tão evidentes quanto eles, encontram-se os estudos feministas e os estudos de gênero, entretanto, por atingirem diretamente os conceitos mais caros da tradição crítica, a crítica pós-colonial conseguiram abrir fissuras mais visíveis na medida em que consegue envolver a discussão do gênero, da raça e da etnia, da classe social e da nacionalidade, dando relevo a todos esses marcadores de diferença. O cânone, apesar de todo o peso da tradição, deixa de estar a eles indiferente e passa a convocá-los, alargando-se.

Resta à crítica a oportunidade de reconhecer e investigar de maneira ampla os fenômenos culturais, sem as limitações disciplinares ou submetida a procedimentos científicos tradicionais. A crítica fica estimulada a questionar, problematizar ou, mesmo, desconstruir o objeto investigado. Certamente, artigos de Stuart Hall, como "What is this "black" in black popular culture? (Rethinking Race)" (Hall 1993) ou "The West and the rest: discourse and power" (Hall 1992), podem se constituir como modelos a esse procedimento crítico de flagrantes dessa interdisciplinaridade. Nesses estudos, Hall parte da análise conjuntural e política dos conceitos, especialmente em "The West and the rest...", como formações discursivas que, atravessando a História, modificam-na e se modificam - no artigo citado, Hall aponta, por exemplo, que "Ocidente" passou a ser um conceito que, deixando de ser uma expressão geográfica, tornou-se uma expressão histórica e cultural, cuja circunscrição espacial de forma alguma é conformada pelo espaço que o termo originalmente designava.

De igual maneira, será a perspectiva de Edward Saïd (1995), quando, por exemplo defende que "a história e a cultura do imperialismo podem ser agora estudadas de maneira não monolítica, sem compartimentos, sem separações ou distinções reducionistas" (Saïd 1995: 22) - visto que, como afirma mais adiante, "a maioria de nós deveria considerar a experiência histórica do império como algo partilhado em comum" (idem: 23). Além disso, Saïd reconhece o estatuto privilegiado da ideia de domínio ultramarino nas culturas dos impérios inglês, francês e norte-americano, ${ }^{5}$ que se encontrava projetada na literatura, na geografia ou nas artes, adquirindo uma presença contínua por meio da expansão, da administração, dos investimentos e dos compromissos efetivos (idem: 24). Ou seja, Saïd reconhece que a cultura do imperialismo se expande para todos os círculos da vida quotidiana dos habitantes do império, não importando onde se localizem, seja na metrópole, seja nas fronteiras mais distantes - todo o conjunto é atravessado e modificado pelo discurso imperial e o modifica, consequentemente.

Ao mesmo tempo, Hall aponta para o fato de que há a necessidade de compreender as hierarquias estabelecidas entre as categorias raciais, construídas pelo pensamento eugenista do século XIX, e que se desdobram nas categorias étnicas do século XX. Os estudos pós-coloniais, tão atentos às relações entre os centros e as fronteiras e as periferias dos impérios, também observa as relações internas entre os diversos agrupamentos que compunham os impérios e que, ainda, subsistem.

Para os estudos de obras literárias, a crítica deve relativizar não apenas a constituição dos sistemas literários das nações envolvidas no colonialismo, mas a questionarem diretamente a 
formação dos cânones e dos discursos que os embasam, seja numa perspectiva interna ao sistema, seja numa perspectiva comparatista entre sistemas, já que se torna possível verificar as formações discursivas que atravessam as obras, os sistemas literários e sua crítica, ${ }^{6}$ a verificarem a dinâmica dos sistemas a partir de um ponto de vista que se exclui do próprio sistema, ao reconhecerem os valores que lhes perpassam, seja para confirmarem ou problematizarem as formações ideológicas. Ao colocarem em evidência questões éticas ou estéticas, dão visibilidade não apenas a obras censuradas, apagadas ou "silenciadas" pela crítica tradicional, mas também aos próprios mecanismos e estratégias de silenciamento operados pelo sistema e que nele se entranharam, constituindo-o e cristalizando-o.

\section{NOTAS}

* Mário César Lugarinho é Professor Associado da Universidade de São Paulo na área de Literaturas Africanas de Língua Portuguesa. É bolsista de produtividade em pesquisa (nível 2) do CNPq, recebendo sucessivos apoios desde 2001. É investigador associado do Centro de Estudos Comparatistas, da Universidade de Lisboa, e do Instituto de Literatura Comparada Margarida Losa, da Universidade do Porto. Foi Professor Visitante na Universidade de Lisboa (2013-2014) e Visiting Scholar na Universidade de Macau (2015-2016). Possui licenciatura em Letras (1989) e especialização em Teoria Literária (1989) pela Universidade do Estado do Rio de Janeiro, mestrado (1993) e doutorado (1997) em Letras pela Pontifícia Universidade Católica do Rio de Janeiro. Fez estágio de pós-doutoramento na Faculdade de Letras da Universidade Federal de Minas Gerais (2002-2003) e no Centro de Estudos Comparatistas da Universidade de Lisboa (2012-2013). Prestou concurso de Livre-docência, para a área de Literaturas Africanas de Língua Portuguesa, na Faculdade de Filosofia, Letras e Ciências Humanas da USP (2012). Foi Professor Associado do Instituto de Letras da Universidade Federal Fluminense, tendo atuado nas áreas de Literatura Portuguesa e Literaturas Africanas de Língua Portuguesa (1994-2007). Com outros pesquisadores, fundou em junho de 2001 a Associação Brasileira de Estudos da Homocultura (ABEH). Publicou livros (Portugal, Brasil), artigos em revistas especializadas e capítulos de livros, no Brasil e no Exterior. Possui experiência na área de Letras, com ênfase em Literaturas Africanas de Língua Portuguesa e Literatura Portuguesa, principalmente nos seguintes temas: Estudos Comparados de Literaturas de Língua Portuguesa, Estudos Pós-coloniais, Estudos Culturais e Estudos Queer.

${ }^{1}$ Ao contrário de A. J. Saraiva que, ao longo de sua obra crítica, não deixou de lado essa aliança em nenhum momento. No caso específico do Brasil, a crítica sociológica teria perdido de vista o caráter específico da obra literária.

${ }^{2}$ Caso característico, sobre o qual não cabe discorrer aqui, seria o tema recorrente do indianismo na Literatura Brasileira; instalado pelo romantismo, sofreu a ação parodística do modernismo e retorna inúmeras vezes na literatura contemporânea, confirmando sua permanência, inclusive pelo viés da problematização. De igual maneira, em Portugal, a recorrência a Camões em suas mais diversas manifestações, desde pelo menos Garrett até Lobo Antunes, que celebrando ou desconstruindo o mito literário, reiteram sentidos que se atualizam, mesmo que pela ação parodística. 
Cadernos de Literatura Comparada

Cânone e Crítica: Superações

${ }^{3}$ A primeira edição, em inglês, foi publicada em 1978.

${ }^{4}$ Listamos os três procedimentos levando em consideração as três práticas investigativas que norteiam as ciências humanas contemporaneamente. A prática do questionamento possui sua raiz na dialética platônica e pode ser considerado como o primeiro procedimento da ciência porque induz à dúvida e, por conseguinte, à busca da verdade. A problematização é procedimento descrito por Michel Foucault, no volume I da História da Sexualidade (1988), e consiste em observar um conceito em toda a sua extensão histórica e cultural, potencializando as formações discursivas que vão se instalando gradualmente nas sociedades, instituindo procedimentos culturais e modificando a História. A desconstrução, descrita pelo também francês Jacques Derrida, é termo que entrou no jargão das Ciências Humanas de maneira imediata, mais pela sugestão semântica, do que pela reflexão que o engendra e proporciona. A desconstrução atua diretamente sobre a relação possível entre texto e contexto, indicando que o sentido se encontra determinado pelo contexto; mas cabe compreender como Derrida estabelece o contexto, pois, se para Foucault e para Pêcheux, a História da Cultura é o lugar do contexto, para Derrida ele está aberto a alterações sucessivas, porque deve considerado sem as fronteiras onde se produz o sentido, já que o contexto e o objeto são construções da linguagem - por isso, qualquer objeto pode ser deslocado e experimentado em qualquer contexto estabelecendo quaisquer sentidos ou interpretações (cf. Spivak 1976).

${ }^{5} \mathrm{~A}$ essa lista acrescentamos, sem dúvidas, o império colonial português.

${ }^{6}$ Se bem que os sistemas não devam ser percebidos de maneira isolada, mas numa intricada rede que os aproxima, o polissistema (Zohar 2013).

\section{Bibliografia}

Althusser, Louis (1992), Aparelhos ideológicos do Estado, $7^{\mathrm{a}}$ ed. Rio de Janeiro, Graal. Anderson, Benedict (2008), Comunidades Imaginadas, São Paulo, Companhia das Letras.

Ashcroft, Bill et alii (org.) (1989), The Empire writes back: theory and practice in post-colonial literatures, London/New York, Routledge.

Barreto, Luis Filipe (1985), Caminhos do saber no renascimento português: estudos de história e teoria da cultura, Lisboa, Imprensa Nacional/Casa da Moeda.

Bloom, Harold (1995), O cânone ocidental: os livros e a escola do tempo, Rio de Janeiro, Objetiva. Cândido, Antônio (2006), Literatura e Sociedade, Rio de Janeiro, Ouro sobre azul.

Costa, Sérgio (2006), "Desprovincializando a sociologia: a contribuição pós-colonial", in Revista Brasileira de Ciências Sociais, 21 (60), fev 2006, pp. 117-134.

Eagleton, Terry (1991), A função da crítica, São Paulo, Martins Fontes.

- - (1997), Teoria da Literatura: uma introdução, $2^{\mathrm{a}}$ Ed. São Paulo, Martins Fontes.

Even-Zohar, Itamar (2013), "Teoria dos polissistema". Translatio (UFRGS), 5, pp. 1-21.

Ferry, Luc (1994), Homo aestheticus: a invenção do gosto na era democrática, São Paulo, Ensaio. Foucault, Michel (1978), Microfísica do poder, Rio de Janeiro, Graal. 
Hall, Stuart (1992), "The west and the rest", in Hall, S. \& Gieben, B. (Eds.), Formations of Modernity, Cambridge (UK), Open University/Polity Press, pp. 275-331.

-- (1993), "'What is this "black' in black popular culture? (Rethinking Race)", in Social Justice, Spring-Summer, 20 (1), pp. 104-15.

Jara, René \& Talens, Jenaro (1987), "Comparatismo y semiótica de la cultura", in Eutopias: Teorias/Historia/Discurso, Minneapolis/Valencia, 3, pp. 5-17.

Lévi-Strauss, Claude (1975), Antropologia Estrutural, Rio de Janeiro, Tempo Brasileiro.

Moreiras, Alberto (2001), A exaustão da diferença: a política dos estudos culturais latino-americanos, Belo Horizonte, UFMG.

Ribeiro, Margarida C. (2008), "Um Desafio a partir do Sul - reescrever as histórias da literatura?", in Veredas, 10, pp. 117-133.

Said, Edward W. (1990), Orientalismo: o oriente como invenção do ocidente, São Paulo, Companhia das Letras.

-- (1995), Cultura e imperialismo, São Paulo, Companhia das Letras.

Santos, Afonso M. dos (1986), "Memória, história, nação: propondo questões", in Tempo brasileiro, 87, pp. 9-18.

Saraiva, António José (1992), A tertúlia ocidental: estudos sobre Antero de Quental, Oliveira Martins, Eça de Queiroz e outros, Lisboa, Gradiva.

Schwarz, Roberto (1976), Ao vencedor, as batatas: forma literária e processo social nos inícios do romance brasileiro, São Paulo, Duas Cidades.

Tinianov, Y. "Da evolução literária", in Todorov, Tzvetan (org.) (1978), Teoria da literatura: textos dos formalistas russos, v. 1, Lisboa, Edições 70, pp. 149-169.

Williams, Raymond (1989), The politcs of Modernism: against the new conformists, London, Verso. 